\title{
Accessory genital glands in the New Zealand White rabbit: a morphometrical and histological study
}

\author{
Joanna Skonieczna ${ }^{1}$, Jan P. Madej ${ }^{1}$, Romuald Będziński ${ }^{2}$ \\ ${ }^{1}$ Division of Histology and Embryology, Faculty of Veterinary Medicine, \\ Wrocław University of Environmental and Life Sciences, 50-375 Wrocław, Poland \\ ${ }^{2}$ Department of Biomedical Engineering, Faculty of Mechanical Engineering, \\ University of Zielona Góra, 65-516 Zielona Góra, Poland \\ sko.joanna1@gmail.com
}

Received: December 13, 2018

Accepted: May 27, 2019

\begin{abstract}
Introduction: The aim of this research was to provide a detailed description of the morphology, topography, and histometry of rabbit accessory genital glands. Material and Methods: Seven male New Zealand White rabbits, 3-4 months of age and weighing $2.1-3 \mathrm{~kg}$ were used for the study. The whole urethra from the urinary bladder to the external urethral orifice accompanied by accessory genital glands was sliced at intervals of $1 \mathrm{~mm}$. The serial sections were prepared with haematoxylin-eosin (H\&E) and Movat-Russell modified pentachrome stain. Results: A detailed description of the morphology and morphometry was provided. The topography of the organs was explained on the basis of characteristic cross-sections on histological slides. The inconsistent nomenclature and descriptions of these glands by different authors were also discussed. Conclusion: The morphometric analysis indicated that some of the glands described have similar dimensions in different individuals, while others like paraprostates revealed high diversity in the number of lobes, their size, and their structure. The accessory glands are also good topographic markers which precisely define the segment of the urethra. The terms "proprostate", "prostate", and "paraprostates" as the nomenclature of the prostate complex reflect the location of these glands well and indicate their common origin and function.
\end{abstract}

Keywords: rabbit, prostate, vesical gland, bulbourethral gland, morphometry.

\section{Introduction}

The accessory genital glands accompany the pelvic part of the urethra. The number and structure of accessory genital glands differ between various mammalian species. The main representatives of these glands are the vesicular gland (glandula vesicularis), prostate (prostata), and bulbourethral gland (gl. bulbourethralis). However, some authors also include the glands of ampulla ( $g l l$. ampullae) that surround the end of the vas deferens in this group (15). These glands are present in dogs, cats, and rabbits.

In carnivorous animals, the prostate is the bestdeveloped accessory gland. In dogs, the prostate occurs as two hemispherical lobes: right and left, which surround the proximal urethra and the neck of the the urethra is free. The disseminated part of the prostate is poorly developed. Holtz and Foote (12) revealed that the prostate in rabbits has a more complex structure. In this animal species, the gland is divided into four parts: the proprostate (proprostata), the prostate (prostata), and two paraprostates (paraprostata). The proprostate and prostate are located dorsally to the urethra, where the proprostate occupies a more cranial position. Both paraprostates are situated laterally to the proprostate and urethra (8). The essential role of the prostate gland is the secretion of the fluid which comprises almost half the volume of semen. This liquid contains an energy source for sperm, stimulates their motility, and is rich in citric acid and proteolytic enzymes (29).

The rabbit vesicular gland, also called the vesicle gland or seminal vesicles (vesiculae seminales), is singular and there are not a pair as there are in humans and other mammals $(2,23)$. It has the appearance of a sack flattened dorsoventrally, bilobed at its cephalic end, and extending bilaterally between the ampullae ductus deferens and the proprostate (12). The ampullae ductus deferens gradually taper off peripherally into one tube, finally to open out into 
the seminal vesicle. The vesicular gland in turn tapers off a little further in the distalmost portion, forming a triangle with the apex directed ventrally (23). It opens into the urethra cranial to the seminal colliculus by a single ejaculatory duct located in the apex (2).

Seminal vesicle fluid is rich in energy substrates, buffering agents, and antioxidants produced for maintaining the functional capacity of the sperm. The secretion of the vesicular gland is responsible for gel plug formation $(7,12)$. This gland has the highest concentration of the lipid hormone prostaglandin, which is however found in all accessory genital glands (4). The prostaglandins are responsible for the contraction of smooth muscle, and it is thought that they stimulate the contraction of the testicular capsule, seminiferous tubules, epididymis, vas deferens, cervix, and uterine body (6). The vesicular gland is not present in dogs or cats.

The bulbourethral glands are uniform, oval organs that are quite apparent in rabbits. They are located dorsal to the urethra and caudal to the prostate (28) in the connective tissue of the urogenital part of the perineum (1). They are surrounded by the bulboglandularis muscle and a thin fibrous capsule. Each one of them is cuboidal in shape, extends in the anterior-posterior sense, and has short ducts ending on the posterior wall of the urethra (25).

In rabbits, the main hormone that stimulates the production of secretions in these glands is testosterone, which is mainly released by the testicles (5). The testes also produce spermatozoa, which combines with seminal plasma secreted by the epididymis and different accessory glands at the time of ejaculation to be semen (9). In rabbits, semen is composed of a fluid part and a gelatinous part. After ejaculation, the gelatinous part fills the lumen of the vagina as a copulation plug (20). In the case of paediatric neutering, the accessory glands remain underdeveloped, but in late-castrated animals, they atrophy.

Rabbits are widely used as laboratory animals and are a good model for studies of function and disorders of the urogenital system $(10,11,13,16,21,30)$. Therefore the structure and morphometry of these organs in the normal condition are a reference point for further studies. In available literature information about the morphology, and particularly the histometry of the urogenital system in New Zealand White rabbits is scarce. Therefore, the aim of the present research was to provide a detailed description of the morphology, topography, and histometry of rabbit accessory genital glands. The nomenclature and description of these glands by different authors are also inconsistent and require unification, and so this work also takes up that task.

\section{Material and Methods}

Seven male New Zealand White rabbits, 3-4 months of age and weighing $2.1-3 \mathrm{~kg}$, were used for the study. They were previously vaccinated against myxomatosis and rabbit viral haemorrhagic disease
(Pestorin Mormyx, Bioveta, Czech Republic). The studies were conducted with the consent of the Local Ethical Committee for Animal Experiments. The rabbits were anaesthetised by an intramuscular injection of xylazine (Sedazin, Biowet Puławy, Poland) at a $5 \mathrm{mg} / \mathrm{kg}$ dose, followed by an intravenous injection of sodium pentobarbital with pentobarbital (Morbital, Biowet Puławy, Poland) at a dose of $80 \mathrm{mg}+16 \mathrm{mg} / \mathrm{kg}$ b.w. The abdominal cavity was opened and the accessory genital glands were removed. The tissues were fixed in $10 \%$ buffered formalin, dehydrated and embedded in paraffin blocks. Sections of $5 \mu \mathrm{m}$ thickness were cut from the accessory glands at intervals of $1 \mathrm{~mm}$. The slices were stained with haematoxylin-eosin (H\&E) and a modified Movat-Russell pentachrome stain (19). The latter stain reveals collagen, elastin, fibrin, and mucin in tissue sections. Collagen with reticular fibres is stained yellow, elastic fibres are stained black to blue, fibrin and muscle are stained red, and mucin is stained bright blue. Histological and morphometrical evaluation was performed using an Eclipse 80i microscope (Nikon, USA) with a camera and the NIS-Elements AR 2.30 software (Nikon). The cross-sectional area and diameter of the organ were estimated in the slide with the highest values of these parameters. The glandular part of the organ was defined as the area of the mucous membrane occupied by glands together with the lumen of the organ or excretory duct. Descriptive statistical analysis was conducted using Statistica 13.1 software (StatSoft, Poland).

\section{Results}

The vesicular gland (seminal vesicle) was a single gland in the shape of flattened sack or eyelid (Fig. 1A). The gland's size was determined by the amount of fluid it contained. As observed in the cross-section, the distal part of this gland was between the proprostate and ampulla ductus deferens, where its lumen was covered by double-lined cylindrical epithelium. From the cranial side, the vesicular gland was bilobed. The wall of this organ was composed of a well-developed mucous membrane which formed low, wide folds reaching a height of $293 \mu \mathrm{m}$ (Fig. 3A). In the distal part, between the folds, large branching crypts invaded the wall of the organ. The surface which lines the lumen of the gland was covered by pseudostratified columnar epithelium (Fig. 3B). The secretory sections invaded the wall of the folds in the form of vesicles which were lined by simple cuboidal epithelium. The cell nuclei were of round or oval shape, and were centrally located. Under the mucous membrane, a moderately developed muscularis composed of smooth muscle fibres and clear adventitia was observed. The gland narrowed caudally to form the ejaculatory duct and opened out into the urethra.

The prostate was seen to be a composite gland comprising a cranially located proprostate (proprostata), 
caudally located prostate (prostata) and two lateral paraprostates (paraprostata) (Fig. 1A). The proprostate and the prostate were attached by a thin connective tissue septum and possessed two independent pairs of excretory ducts. In both organs, the excretory ducts left through the ventral surface of these glands. The proprostate was a tubular-follicular gland with trabeculae that connected the opposite walls of the organ (Fig. 2A). The secretory sections were lined by simple cylindrical or double-row cylindrical epithelium with eosinophilic cytoplasm. Cell nuclei of round or oval shape were located centrally, or slightly closer to the base, with the longer diameter directed perpendicular to the basement membrane. The apical part of the epithelial cells contained granular material which was excreted into the lumen of the gland in an apocrine manner. The Movat stain revealed different types of glandular cells by giving them different colours. One type were cells producing a protein-rich secretion and the other were cells producing a glycosaminoglycan (GAG)-rich secretion. The parenchyma of the proprostate gland contained adequately vascularised loose connective tissue with strands of smooth muscle cells that surrounded the organ and invaded the trabeculae. In the histological image, numerous collagen fibres and few elastic fibres were observed. The prostate was a tubular gland that was surrounded by a connective tissue capsule which was shared with the proprostate. An excretory duct left through the ventral surface of each lobe and lay dorsal to the proprostatic duct. Bands of connective tissue divided the parenchyma into lobules (Fig. 2B). In the cross-section, the mean area of the glandular part was $24.5 \pm 4.7 \mathrm{~mm}^{2}$ (Table 1 ). The secretory sections were lined with a single cylindrical epithelium (Fig. 2C and E). Oval cell nuclei were located in the basal part of the cells and arranged in a manner wherein the longer diameter was parallel to the basement membrane. The intensely eosinophilic cytoplasm contained some granules. In the lumen of the secretory sections, eosinophilic secretions with spherical form were observed. They were called corpus amylacea, occurred only in the prostate (Fig. 2D and Table 1), and were uncalcified, laminated, and of different sizes. The parenchyma of the prostate, in contrast to that of the proprostate, contained a small number of smooth muscle cells. The paraprostates were small glands in the shape of a butterfly or a clover (Fig. 2F) present singly or as a pair on each side of the urethra (two to four per animal). The cross-sectional area of each lobe was highly diversified even in one individual (Table 1). The secretory sections constituted vesicles or short tubules lined by simple cuboidal epithelium (Fig. 2G). The efferent ducts were covered by simple cylindrical epithelium, and located lateral to the ducts of the prostate and proprostate.

The bulbourethral glands (Cowper's glands) were complex glands and consisted of two lobes located one on each side of the urethra (Fig. 1B). The lobes were distinctly demarcated from each other, and their ducts were observed on or around the colliculus seminalis. Cowper's glands were embedded in the bulboglandular muscle. The cross-sectional area of the glandular part of each lobe was $3.15-6.12 \mathrm{~mm}^{2}$ (Table 1).

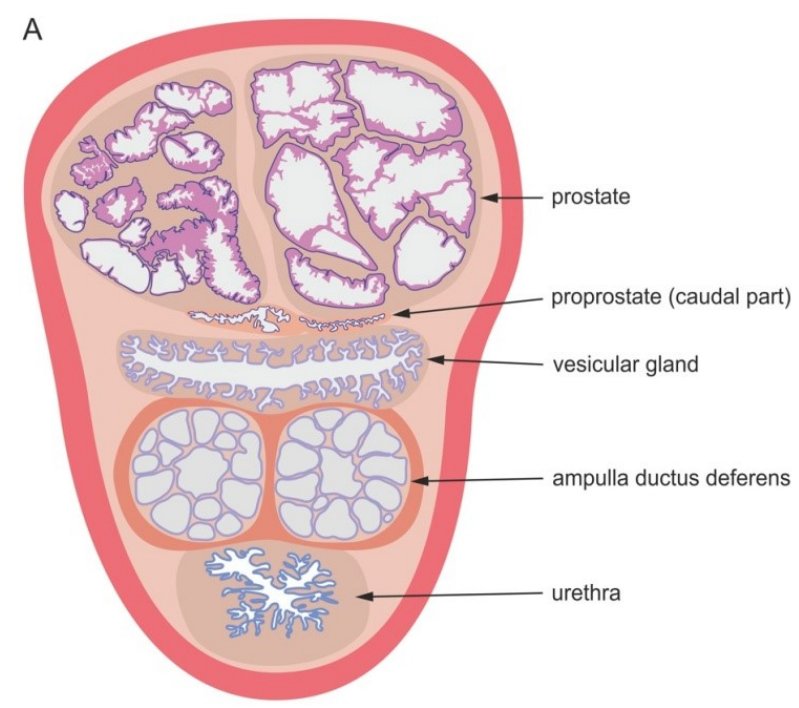

B

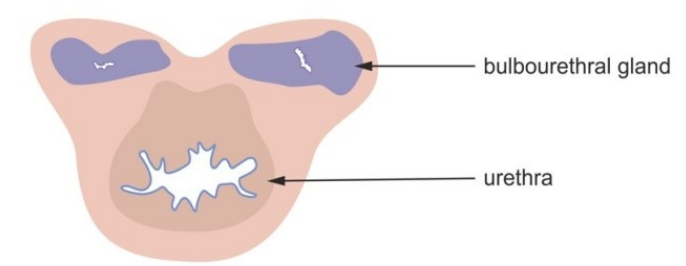

Fig. 1. Scheme of rabbit accessory genital glands in cross-section, at the level of the prostate complex (A) and caudally from colliculus seminalis (B) 
Table 1. Morphometrical data of New Zealand White rabbit accessory genital glands

\begin{tabular}{|c|c|c|}
\hline Organ (cross-section) & Mean \pm SD & Min-Max \\
\hline \multicolumn{3}{|l|}{ Prostate } \\
\hline area of the glandular part & $24.5 \pm 4.7 \mathrm{~mm}^{2}$ & $20.1-29.5 \mathrm{~mm}^{2}$ \\
\hline diameter of corpus amylacea & $46.6 \pm 26.1 \mu \mathrm{m}$ & $19.1-113.2 \mu \mathrm{m}$ \\
\hline \multicolumn{3}{|l|}{ Paraprostates } \\
\hline area of each lobe & $0.79 \pm 0.54 \mathrm{~mm}^{2}$ & $0.43-1.94 \mathrm{~mm}^{2}$ \\
\hline \multicolumn{3}{|l|}{ Bulbourethral (Cowper's) glands } \\
\hline area of the glandular part from each lobe & $4.33 \pm 1.28 \mathrm{~mm}^{2}$ & $3.15-6.19 \mathrm{~mm}^{2}$ \\
\hline \multicolumn{3}{|l|}{ Ampullae ductus deferens } \\
\hline area of proximal segment & $5.29 \pm 0.58 \mathrm{~mm}^{2}$ & $4.77-5.93 \mathrm{~mm}^{2}$ \\
\hline diameter of proximal segment & $2.58 \pm 0.13 \mathrm{~mm}$ & $2.47-2.73 \mathrm{~mm}$ \\
\hline area of distal segment (by the ostium) & $2.64 \pm 1.07 \mathrm{~mm}^{2}$ & $1.12-3.88 \mathrm{~mm}^{2}$ \\
\hline diameter of distal segment & $1.89 \pm 0.43 \mathrm{~mm}$ & $1.17-2.21 \mathrm{~mm}$ \\
\hline area of the glandular portion in proximal segment & $3.99 \pm 0.79 \mathrm{~mm}^{2}$ & $3.26-4.94 \mathrm{~mm}^{2}$ \\
\hline diameter of the glandular portion in proximal segment & $2.33 \pm 0.22 \mathrm{~mm}$ & $2.20-2.59 \mathrm{~mm}$ \\
\hline area of the glandular portion in distal segment & $1.47 \pm 0.46 \mathrm{~mm}^{2}$ & $0.89-2.16 \mathrm{~mm}^{2}$ \\
\hline diameter of the glandular portion in distal segment & $1.39 \pm 0.32 \mathrm{~mm}$ & $0.89-1.72 \mathrm{~mm}$ \\
\hline
\end{tabular}
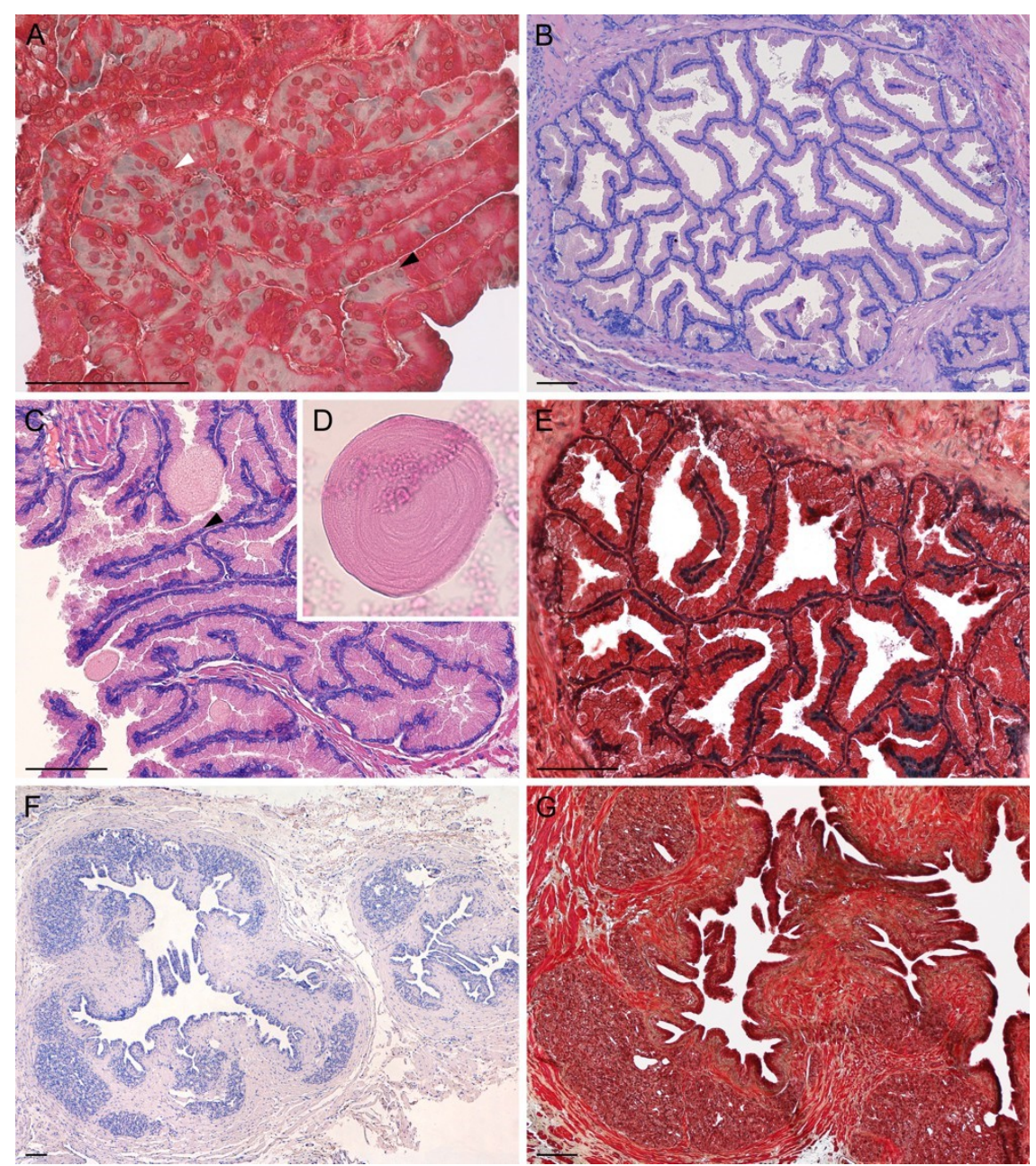

Fig. 2. Rabbit prostate complex. A - proprostate; note the presence of two differently stained types of glandular cells (arrowheads); B, C and E - prostate; note the basally located nuclei and acidophilic cytoplasm of epithelial cells (arrowheads); D - corpus amylacea; F and G - paraprostate; note the resemblance of the parenchyma structure to that of the bulbourethral gland. Scale bar: $100 \mu \mathrm{m}$. Original magnification: $40 \times(\mathrm{F}), 100 \times(\mathrm{B}$ and $\mathrm{G}), 200 \times(\mathrm{C}$ and $\mathrm{E}), 400 \times(\mathrm{A})$

They were located caudally to the prostate and dorsally to the urethra. The abundant connective tissue divided lobes into several lobules (Fig. 3E) and the interlobular connective tissue was accompanied by bundles of muscle fibres and clearly visible blood vessels (Fig. 3F). Some strands of interlobular connective tissue were penetrated by irregularly oriented, striated muscle fibres. The secretion from each 
lobe was led out by a single efferent duct with folded lumen and lined with simple cylindrical or pseudostratified epithelium. These efferent ducts opened out on the dorsal wall of the urethra. The secretory sections with tubular follicular shape were covered by simple cylindrical epithelium and produced a mucous secretion. This variety of glandular cells had round or slightly oval nuclei which were located mainly in the basal part of the cytoplasm. The structure of this epithelium was similar to that of the paraprostates. The efferent ducts began with inserts which were noticed in the lumen of secretory sections. Further, the efferent ducts drained to the interlobular ducts lined by simple cylindrical epithelium. The cell nuclei of this segment were oval and centrally located, while the cytoplasm was slightly eosinophilic.

The ampullae ductus deferens (ampulla of vasa deferentia) were located between the vesicular gland and urethra. The cross-section revealed that each ampulla was round in shape and composed of a mucous membrane, muscularis, and adventitia. In the cranial (proximal) segment, they were large, with areas of 4.77-5.93 $\mathrm{mm}^{2}$ (Table 1). In the caudal (distal) direction, their diameter gradually decreased, their areas contracting to $1.12-3.88 \mathrm{~mm}^{2}$ near the ostium. The mucous membrane was well developed and contained long crypts lined with cylindrical partially ciliated epithelium which extended from the main lumen. There were also large, circular or oval glands that were lined with cuboidal or sometimes even squamous epithelium (Fig. 3C and D). These glands opened to the main lumen or to the crypts. The glandular/inner portion of the ampulla ductus deferens occupied an area of approximately $3.26-4.94 \mathrm{~mm}^{2}$ in the cranial segment and $0.89-2.16 \mathrm{~mm}^{2}$ in the caudal segment (Table 1). In Movat staining, the lumen of glands was filled with dense blue fluid, which indicated high GAG content. A thin smooth circular muscle layer and poorly developed connective tissue with blood vessels were observed. The ampullae ductus deferens gradually constricted and opened out on the ventral wall of the vesicular gland.

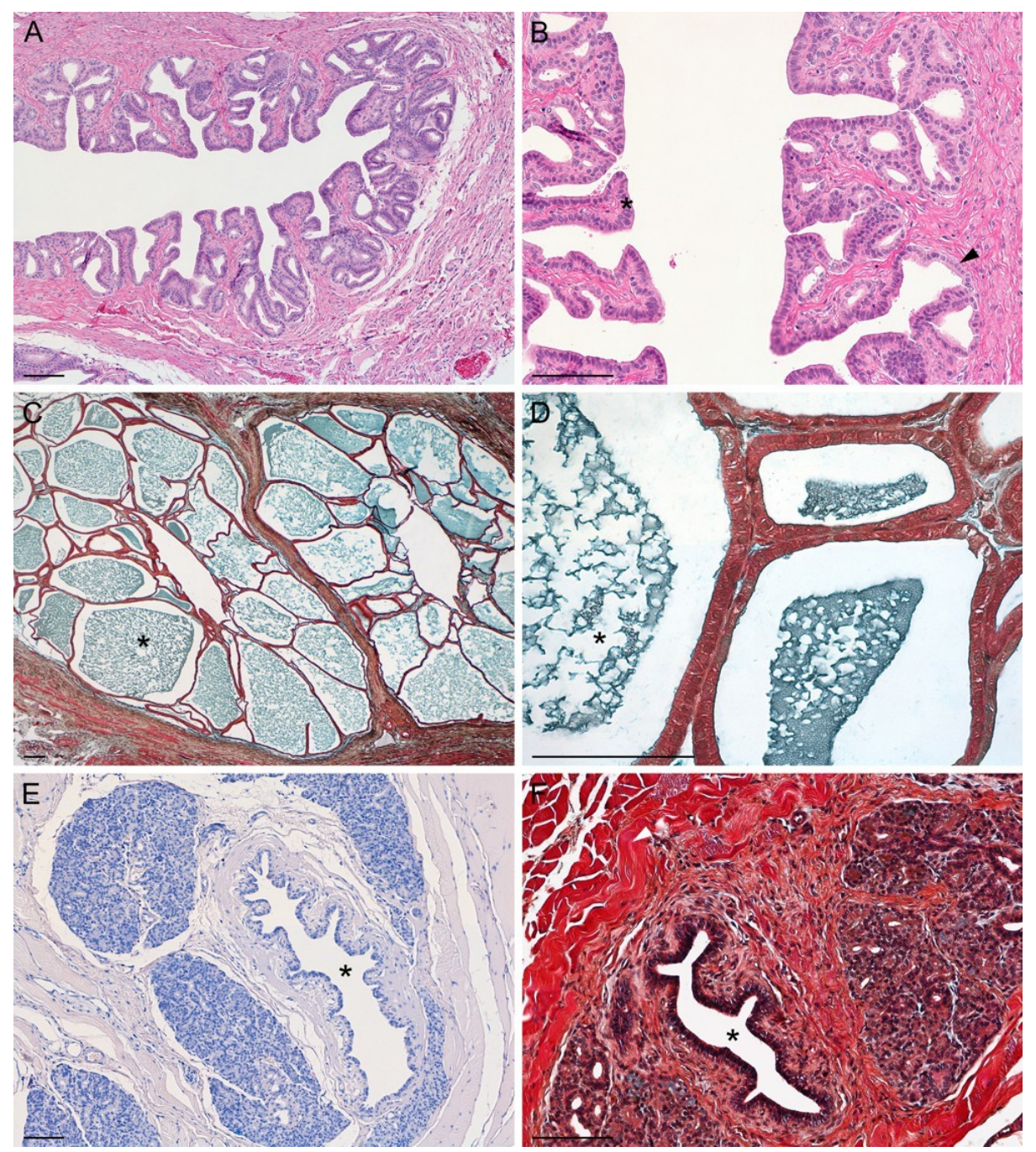

Fig. 3. A and B - vesicular gland; folds of the mucous membrane covered by pseudostratified (asterisk) or single columnar (arrowhead) epithelium; C and D - ampulla ductus deferens; the excretion is present in the lumen of the glands (asterisk); $\mathrm{E}$ and $\mathrm{F}$ - the bulbourethral gland surrounded by the bulboglandular muscle (arrowhead); note the large excretory duct (asterisk). Scale bar: $100 \mu \mathrm{m}$. Original magnification: 40× (C), $100 \times(\mathrm{A}$ and $\mathrm{E}), 200 \times(\mathrm{B}$ and $\mathrm{F}), 400 \times(\mathrm{D})$ 


\section{Discussion}

The rabbit urogenital system is a good model that enables testing of new drugs or implants that have potential to be used in human or veterinary medicine. The accessory genital glands can be studied simply as such, but they are also a very useful topographic marker for the description of the consecutive sections of the urethra. This paper provides morphometrical data with a detailed histological description of normal accessory genital glands in rabbits, which are a good reference point for pathological work or planning surgical approaches.

The vesicular gland was previously characterised in 4-9 month-old (1.6-2.4 kg b.w.) Dutch rabbits by Bern (2) as a tubuloalveolar gland that consisted of three types of epithelial cells in a glandular portion: surface, neck, and glandular. He described the surface epithelium as pseudostratified columnar where the cytoplasm was slightly granular with large nuclei which occupy no constant position. The narrow columnar cells in the neck had compressed nuclei, and the cells at the base of the glands possessed large basal nuclei. The glandular wall was surrounded by a heavy fibromuscular layer. Rokkaku et al. (22) indicated that the mucous of the vesicular gland formed secondary and even tertiary folds. The epithelium of the mucous folds was singlerow and cylindrical, becoming double-row in the distal portion near the orifice of the ampullae, and the muscularis was very ill-developed. We observed mucous folds lined by pseudostratified columnar epithelium. Additionally, the secretory sections of the glands invaded the wall of folds, taking the shape of vesicles covered by simple cuboidal epithelium. The muscle membrane was moderately developed, but externally located adventitia was clearly visible.

The prostate in the study of Bern (2) was described as a tubuloacinar gland with villus-like infoldings, which cross-sections taken through the alveolar walls presented. Further studies confirmed that the prostate is a complex organ with four excretory ducts (22) leading from separate parts of this gland. Finally, Holtz and Foote (12) divided the prostate of the rabbit into four parts: proprostate, prostate, and two paraprostates. In our studies, we have classified the proprostate as a compound tubuloacinar gland, the prostate as a compound tubular gland, and the paraprostates as compound tubuloacinar glands.

In the study on Dutch rabbits (mean age 21.2 months, mean body weight $2.02 \mathrm{~kg}$ ), Holtz and Foote (12) revealed that each compartment of the proprostate is lined with columnar cells of varying height with centrally located, round nuclei, and is surrounded by a single layer of flat fibrocytes with compressed nuclei. In our research, we also observed the simple cylindrical epithelium, but cell nuclei of round or oval shape were located centrally or slightly closer to the base. The shape and location of the nuclei probably depend on the physiological state of the cells and on secretion, i.e. the phase of its accumulation and excretion. Interestingly, using Movat's stain, we revealed two differently stained types of glandular cells. The question arises whether these two types of cells represent different physiological states or whether there are two independently differentiated cells.

Previous studies have shown corpora amylacea as a characteristic feature of the mammal prostate and indicated that their number increases with the age of the organism $(22,24,29)$. We found that corpora amylacea are clearly visible in young rabbits.

In the paraprostates, the epithelium of the secretory sections was found to be similar to that occurring in the bulbourethral glands. Some authors discovered the second type of epithelium which is congruent to that in the prostate, but this situation was not observed in all individuals $(3,12,26)$. Another interesting issue is the number of paraprostates. In the study of Holtz and Foote (12), every rabbit had at least one bilateral pair of paraprostates, whereas some rabbits had two glands on one or both sides. However, Bern and Krichesky (3) reported up to five paraprostates on one side of the urethra and up to three small examples on the other side. In our study, we observed two pairs of paraprostates on both sides of the urethra. However, Vásquez and del Sol (27) observed only one paraprostate on each side of the urethra in all the studied rabbits.

The present study indicated that the nuclei of secretory cells in the bulbourethral glands are located in the basal part of the cytoplasm, while Holtz and Foote (12) described the apical distribution of these organelles. The differences in nuclei location are probably related to the different phases of secretion of the produced substances.

In conclusion, the accessory genital glands in rabbits are a good model in which to study the influence of selected drugs directly on these organs in mammals. Moreover, they are also good topographic markers that precisely define the segment of the urethra, for example in surgical procedures tested in the urethra. The morphometric analysis indicated that some of the glands described had similar dimensions in different individuals, while others like paraprostates revealed high diversity in the number of lobes, their size, and their structure. In the opinion of the authors of this article the nomenclature of the prostate complex in the scheme of proprostate, prostate, and paraprostates, as proposed by Holtz and Foote (12), reflects the location of these glands well and indicates their common origin and function.

Conflict of Interests Statement: The authors declare that there is no conflict of interests regarding the publication of this article. 
Financial Disclosure Statement: This research was financed by grant no. DEC-2016/21/B/ST8/01972 from the National Science Centre in Kraków (Poland).

Animal Rights Statement: The studies were conducted with the consent of the Local Ethical Committee for Animal Experiments as documented in record no. 1/2017 and under the guidelines for experimentation on animals.

\section{References}

1. Barone R.: Splanchnologie II. In: Anatomie comparée des mammifères domestiques. $^{\text {th }}$ vol., Vigot. Paris 2001, pp. 159-185.

2. Bern H.A.: The effects of sex steroids on the sex accessories in the male Dutch rabbit. Am J Anat 1949, 84, 231-278.

3. Bern H.L., Krichesky B.: Anatomic and histologic studies of the sex accessories of the male rabbit. Univ Calif Publ Zool 1943, 47, 175-196.

4. Bromfield J.J., Ibrahim L.A., Rizo J.A.: Seminal vesicle gland overview. In: Encyclopedia of reproduction, edited by M. Skinner, Elsevier, Gainesville 2018, pp. 341-343.

5. Castro A.C.S., Berndtson W.E., Cardoso F.M.: Plasma and testicular testosterone levels, volume density, and number of Leydig cells and spermatogenic efficiency of rabbits. Br J Med Biol Res 2002, 35, 493-498.

6. Da Silva B.F., Meng C., Helm D., Pachl F., Schiller J., Ibrahim E., Lynne C.M., Brackett N.L., Bertolla R.P., Kuster B.: Towards understanding male infertility after spinal cord injury using quantitative proteomics. Mol Cell Proteomics 2016, 15, 1424-1434.

7. Del Niño Jesus A., Muñoz L., Josa A., Espinosa E., Gracia M., Martinez G., Leuza M.P.: Modifications of some parameters of the rabbit ejaculate after ablation of the vesicular gland. World Rabbit Sci 1997, 5, 3-5.

8. Dimitrov R.S., Stamatova K.: Comparative ultrasonographic study of the prostate complex and bulbourethral glands of the domestic rabbit (Oryctolagus cuniculus). J Vet Res Animal Sci 2011, 35, 201-205.

9. El-Azim A.A., El-Kamash E.M.: Evaluation of semen quality and its relation to mating system for some breeds of rabbits under environmental conditions in the middle of Egypt. Egyptian Poultry Sci J 2011, 31, 467-480.

10. Faydaci G., Tarhan F., Tuncer M., Eryildirim B., Celik O., Keser S.H., Ozgül A.: Comparison of two experimental models for urethral stricture in the anterior urethra of the male rabbit. Urology 2012, 80, 225e7-225e11.

11. Feng B., Zhang Y., Mu J., Ye Z., Zeng W., Qi W., Luo Z., Guo Y., Yang X., Yuan F.: Preventive effect of a proteasome inhibitor on the formation of accelerated atherosclerosis in rabbits with uremia. J Cardiovasc Pharmacol 2010, 55, 129-138.

12. Holtz W., Foote H.: The anatomy of the reproduction system in male Dutch rabbits (Oryctolagus cuniculus) with special emphasis on the accessory sex glands. J Morphology 1978, 158, 1-20.
13. Huang S.L., Fu D.L., Li H.C., Zhang P., Chong T.: The effect of rapamycin on TGF $\beta 1$ and MMP1 expression in a rabbit model of urethral stricture. Int Urol Nephrol 2016, 48, 717-723.

14. Kallel F., Prince R.E., Konofagou E., Ophir J.: Elastographic imaging of the normal canine prostate in vitro. Ultrason Imaging 1999, 21, 201-215.

15. König H.E., Liebich H.G.: Veterinary anatomy of domestic mammals - textbook and colour atlas. Schattauer, Stuttgart 2014, pp. 389-391.

16. Li G., Wu Y.Y., Fu W.J., Jia Y.X., Zhang B.H., Xu Y.D., Wang Z.X., Shi J.G., Tan H.S., Qian Y.Y., Shi B.Y., Zhang Ch.H., Wang X.X.: Study of clinical practical model of urinary system injury. Chin Med J 2015, 128, 928-932.

17. McCracken T.O., Kainer R.A.: Color atlas of small animal anatomy: the essentials. Blackwell Publishing, Ames, 2008, p.72.

18. Mitchell M.A., Tully T.N.: Current therapy in exotic pet practice. Elsevier, St. Louis, 2017, pp. 464-466.

19. Mukherjee D.P., Johari M.P., Bhattacharya P.: The gelatinous mass in rabbit semen. Nature 1951, 168, 422-423.

20. Nuininga J.E., Koens M.J., Tiemessen D.M., Oosterwijk E., Daamen W.F., Geutjes P.J., van Kuppevelt T.H., Feitz W.F.: Urethral reconstruction of critical defects in rabbits using molecularly defined tubular type I collagen biomatrices: key issues in growth factor addition. Tissue Eng Part A 2010, 16, 3319-3328.

21. Röcken C., Linke R.P., Saeger W.: Corpora amylacea in the lung, prostate, and uterus. A comparative and immunohistochemical study. Path Res Pract 1996, 192, 998-1006.

22. Rokkaku K., Saito R., Watanabe S., Baba Y.: On the fine structure of urogenital organs in male rabbit. Arch Histol Jpn 1960, 21, 2340.

23. Russell H.K. Jr.: A modification of Movat's pentachrome stain. Arch Pathol 1972, 94, 187-191.

24. Smith M.J.V., Chir B.: Prostatic corpora amylacea. Monogr Surg Sci 1966, 3, 209-265.

25. Vásquez B., del Sol M.: Estudio morfológico de la glándula bulbouretral de conejo (Oryctolagus cuniculus). Rev Chilena Anatomia 2001, 19, 221-228.

26. Vásquez B., del Sol M.: Complejo prostático en el conejo (Oryctolagus cuniculus). Rev Chilena Anatomia 2002, 2, 175-180.

27. Vásquez B., del Sol M.: Estereología comparativa entre las glándulas del complejo prostático del conejo oryctolagus cunniculus. Int J Morphol 2009, 27, 205-210.

28. Vásquez B., del Sol M.: Estereologia das glândulas bulbouretrais do coelho (Oryctolagus cuniculus) e da cobaia (Cavia porcellus). Pesq Vet Bras 2014, 34, 1247-1250.

29. Young B., Lowe J.S., Stevens A., Heath J.W., Deakin P.J.: Wheater's functional histology: a text and colour atlas. Elsevier, London, 2006, pp. 355-357.

30. Zhang K., Guo X., Zhao W., Niu G., Mo X., Gu Q.: Application of wnt pathway inhibitor delivering scaffold for inhibiting fibrosis in urethra strictures: in vitro and in vivo study. Int J Mol Sci 2015, 16, 27659-27676. 